\title{
A constituição dos relatos de experiência como um gênero na formação de professores
}

\section{Betânia Passos Medrado}

Professora adjunto I do Departamento de Letras

Estrangeiras Modernas e do Programa de Pós-

Graduação em Lingūistica - Proling - da UFPB.É editora da Revista Letr@Viv@.Seusinteresses de pesquisa estão voltados para a formação docente com foco na reflexão crítica e na construção identitária de professores de línguas. Atua também nas seguintes áreas: linguística aplicada, letramento docente, gêneros textuais, metodologia do ensino de lingua estrangeira e lingüistica cognitiva.

Resumo: Na formaçâo continuada de professores, a reflexão sistemática sobre a sala de aula tem se tornado uma prática que envolve grupos e comunidades de professores. Este artigo objetiva analisar a constituiçäo dos relatos de experiência como um gênero, alinhando-se aos pressupostos da escola socio-retórica dos estudos de gênero (MILLER, 1984, 1994), que atesta que os gêneros servem para ajudar as pessoas a se reproduzirem e se reconstruírem, a continuarem sua própria história.

Palavras-chave: formaçāo de professores; relatos de experiência; gênero
Abstract: In language teacher development, the systematic reflection upon the language classroom has become a practice which involves groups and communities of teachers. This article aims at analyzing the constitution of teachers' narratives as a genre, taking into consideration the assumptions of the social rhetoric school (MILLER, 1984, 1994) which claims that genres serve to help real people to reproduce and reconstruct themselves, to continue their stories.
Key-words: teacher development; teachers' narratives; genre 



\section{Introdução}

Hoje é senso comum afirmar que a nossa sociedade é semiotizada, textualizada e que os gêneros sempre existiram, haja visto que a língua só se manifesta através deles. No entanto, essa conscientização de que textualizamos o mundo e que os textos se constituem enquanto gênero é relativamente recente.

A ênfase no estudo da forma no campo da Lingüística prorrogou para o final do século XX a visão de língua como mediadora dos processos de interação (MONDADA, 2002), e de mudança social (FAIRCLOUGH, 2001). Assim, os estudos de gênero, em contrapartida ao pensamento formalista, propõem uma análise de textos na qual são importantes aspectos, tais como: por que, para quem, em quais circunstâncias e com quais propósitos os textos são escritos. Esta perspectiva extrapola a análise da forma pela forma, e cria, como afirma Bhatia (1993), uma consistente e profunda descrição de textos acadêmicos e profissionais que têm se tornado "[...] um instrumento útil e poderoso para se chegar a significantes correlações entre forma e função"(p. 11) ${ }^{1}$.

Os relatos de experiência têm se tornado uma ferramenta imprescindível na educação continuada de professores, uma vez que, nas suas narrativas, os professores reconstroem a prática e corporificam seus conhecimentos, subsidiando sócio-política e culturalmente a ação pedagógica. Enquanto manifestação textual de impressões de práticas docentes, o relato vem se estabelecendo como elemento organizador de uma prática discursiva, a partir do momento em que esses textos servem para divulgar conhecimentos, esteja o foco na metodologia ou, simplesmente, nas experiências vividas pelo professor.

Ao lançarmos um olhar sobre o relato de experiências de professores, a partir de uma perspectiva funcional, passamos a concebê-lo como um discurso que, além de registrar e legitimar uma prática, estabelece, sobretudo, significados que constroem e (re)significam mundos (FAIRCLOUGH, 2001). Esta visão não deixa de ser etnometodológica, uma vez que permite, até certo
1 " [...] a powerful and useful tool to arrive at significant formfunction correlations $[\ldots] "$ 
2 " [...] virtual communities, the relationships we carry around in our heads, to reproduce and reconstruct themselves, to continue their stories." ponto, que se tenha acesso ao conhecimento do professor que cria a experiência, e é por ela criado.

Assumindo, então, que o refletir do professor tem se tornado uma prática também social, envolvendo comunidades de professores, propomos estabelecer, neste artigo, uma relação teórica entre o discurso desses professores e os pressupostos da escola americana (concepção sócio-retórica) dos estudos de gênero que atesta que estes servem para ajudar não só as pessoas reais a realizarem seu trabalho e atingirem seus objetivos, mas também ajudam "[...] comunidades virtuais, as relações que carregamos em nossas mentes, a se reproduzirem e se reconstruírem, a continuarem suas histórias"2 (MILLER, 1994, p. 75).

\section{Breves considerações sobre gênero}

Atualmente, podemos classificar ou organizar os estudos de gênero em, pelo menos, quatro diferentes perspectivas ou tendências com base numa ênfase mais ou menos sociológica, antropológica ou lingüística que essas pesquisas dão à concepção de gênero: 1 . concepção sócioretórica de gênero (MILLER, 1984,1994; BAZERMAN,1994; SWALES 1990,19992; BHATIA, 1993); 2. concepção sistêmico-funcionalista (HALLIDAY e HASAN, 1989); 3. concepção enunciativa (BAKHTIN, 2000); 4. concepção sócio-construtivista (BRONCKART, 2003; SCHNEWLY e DOLZ, 1996, 1998).

É preciso reiterar que, na sua interseção, essas perspectivas reconhecem que os gêneros são dinâmicos e históricos, e que o seu estudo envolve muito mais do que uma observação meramente lingüística de textos; envolve, ainda, uma concepção na qual eles constituem formas de ação social que dizem o mundo. Abarcam, não somente aspectos sociais e históricos, mas também permitem uma investigação de textos efetivamente vinculados à vida institucional de um determinado grupo de profissionais. 
No entanto, houve, por muito tempo, uma preocupação premente em estabelecer taxonomias na busca de classificações definitivas dos gêneros do discurso ${ }^{3}$. Hoje, contudo, as pesquisas compõem um campo interdisciplinar que sugere não apenas classificações, mas também a organização de conceitos, e a observação de como uma análise interna dos gêneros pode ser realizada. Isto é, não fazem nem tipologia, nem análise stricto sensu. Essas investigações têm permitido o intercâmbio de idéias frutíferas em relação à língua e a sua função comunicativa e têm, de certa forma, contribuído para o deslocamento do foco de uma análise lingüística da estrutura para uma análise, não só da função do texto, mas também de seus aspectos sociais, históricos e culturais.

Sabemos que os gêneros resultam da complexidade da organização social, e novos gêneros surgem à medida que outros tipos de discurso emergem para dar conta de novas interações sociais. Esta posição é ratificada por Bronckart (2003), quando afirma que a emergência de uma espécie de texto pode estar relacionada ao surgimento de novas motivações sociais. $O$ autor, entretanto, conclui que “[...] algumas novas espécies de textos podem não ter ainda recebido um nome consagrado, em termos de gênero"(2003; p. 74).

Para tratar dessa questão, tomamos como central a premissa de que "[...] os gêneros textuais são fenômenos históricos, profundamente vinculados à vida cultural e social"(MARCUSCHI, 2002a, p. 19). Com isso em mente, estaremos aqui considerando que os relatos produzidos por professores, quando no processo de reflexão sobre seu fazer pedagógico, constituem um gênero discursivo que tem legitimado e disseminado a ideologia de uma prática reflexiva na formação de professores. Este posicionamento nos é assegurado através da seguinte assertiva de Bronckart (2003; p. 73): “[...] qualquer espécie de textopode atualmente ser designada em termos de gênero e que, portanto, todo exemplar de texto observável pode ser considerado como pertencente a um determinado gênero".
${ }^{3}$ Como nos trabalhos de Weinrich e Virtanen, nas décadas de 70 e 80 do século passado. 
${ }^{4}$ A rhetorical community (...) is just such a virtual entity, a discursive projection, a rhetorical construct. It is the community as invoked, represented, presupposed, or developed in rhetorical discourse. It is constituted by attributions of characteristic joint rhetorical actions, genres of interaction, ways of getting things done, including reproducing itself.

\section{O gênero relato na formação de professores}

Lembremos que os gêneros são, pela sua natureza, atividades coletivas, pois embora pertençam a indivíduos, são administrados, digamos assim, por grupos a partir de um local sócio- histórico. Assumir, então, a reflexão (formal ou informal) como exercício da prática diária docente faz constituir um grupo que reconhecemos se adequar bem à definição de comunidade retórica, tal como entendida por Miller (1994). Esta comunidade não existe em uma área específica, uma vez que não podemos localizá-la geográfica ou demograficamente. Entretanto, ela existe naquilo que podemos reconhecer das suas interseções discursivas, e que demonstram conhecer os membros desta comunidade na/da sua prática:

Uma comunidade retórica... é precisamente essa entidade virtual, uma projeção discursiva, um construto retórico. É a comunidade tal como invocada, representada, pressuposta ou desenvolvida no discurso retórico. É constituída pelas atribuições de ações retóricas conjuntas características, gêneros de interação, modos de produzir ações, incluindo a auto-representacão (grifos nossos) (MILLER, op.cit, p.73) ${ }^{4}$.

O relato de experiências de professores tem sido um instrumento imprescindível para compreender e transformar suas ações em sala de aula. Estamos, de fato, tratando de um discurso que emerge em uma prática que se apresenta não só como veiculadora de inúmeros valores sociais, culturais e institucionais, que refletem o pensar e o fazer de um grupo, mas também como possuidora de um potencial para reproduzir e influenciar a forma de pensar e agir de um grupo. $\mathrm{O}$ relato constitui um procedimento autobiográfico que permite ao professor uma melhor compreensão das suas ações, evidenciando uma prática social permeada por 
uma conscientização da metodologia, da linguagem e da representação de si mesmo.

De fato, a noção de comunidade perpassa vários campos de estudo. Na sociolingüística, a comunidade de fala (HYMES, 1972) refere-se a indivíduos que formam redes de contatos efetivos, que mantêm uma relação interna ou relações sociais. Para Swales (1990), os gêneros são realizados em comunidades discursivas originadas no contexto da etnografia, entendidas como um grupo de sujeitos que têm interesses específicos, formando redes socio-retóricas. Nesta comunidade, tendem a predominar nas necessidades comunicativas, e os objetivos no desenvolvimento e manutenção das características discursivas. Para Marcuschi (2002, mimeo, material didático não publicado), a comunidade de fala sociolingüística é centrípeta, uma vez que une os seus membros em interesses sociais comuns desde o nascimento. Por outro lado, a comunidade discursiva é centrífuga, pois os seus membros estão separados em interesses ocupacionais e profissionais de acordo com treino, competência, interesses e funções na sociedade.

Entretanto, aquela definida por Miller como comunidade retórica se insere, perfeitamente, no nosso entendimento do grupo de professores que se diz reflexivo ou está realizando práticas reflexivas sobre a sua prática pedagógica. Para Miller (1994, p.74), uma comunidade atua retoricamente quando opera através do gênero, na ação social reproduzida, na relação entre o macro e o micro, o público e o privado, o singular e o recorrente. Sobre isto, é bom frisar que a comunidade retórica inclui o outro, isto é, ela inclui o mesmo e o diferente, o eu e o nós, o consenso e o dissenso, o partilhado e o único.

Interessante observar que esse outro emerge no discurso do professor como colegas (outros professores), a instituição, seus alunos ou até ele mesmo, evidenciando as múltiplas comunidades das quais cada indivíduo participa. Vejamos alguns fragmentos de relatos de experiências de professores ${ }^{5}$.
${ }^{5}$ Excertos de falas que fazem parte do corpus da pesquisa de doutorado ESPELHO, ESPELHO MEU: um estudo sociocognitivo sobre a conceptualização do fazer pedagógico em narrativas de professores, orientada pela Profa. Dra.

Abuêndia Padilha Pinto, e defendida na UFPE em 2006. 
Professora $C$.

mas eu acho que foi muito tempo naquela primeira atividade/ eu acho que teria dado tempo de ter feito as duas coisas de ter feito a carta e já o reply até porque ficou muito perdido o que aconteceu/ que a reply alguns entregaram na outra aula outros não entregaram / e aí ficou meio perdida a idéia

\section{Professora $I$.}

eu acho/eu acho que eu complico muito dando instrução com medo deles não entenderem ((pausa longa)) eu sinto muita dificuldade porque eu percebo que muitas das instruções que eu dou deve ter um gap não é? / em algum momento em que muitas vezes o feedback não é o que eu espero/ ai eu tento detalhar e quanto mais eu detalho pior fica

Nesses exemplos, podemos observar que as professoras comentam as suas ações em sala de aula. A professora L avalia uma atividade solicitada aos alunos e, ao mesmo tempo, a reconstrói, sugerindo alternativas para as suas próprias ações. Já a professora I avalia a sua habilidade de dar instruções aos alunos. Partem as professoras, nesses dois relatos das situações em sala de aula, no nível micro - para o que é legitimado e institucionalizado pelo livro didático, pela autoridade metodológica ou pela escola, no nível macro - como vemos a seguir:

\section{Professora $I$.}

a escola em que eu ensino a metodologia é completamente assim diferente do que a gente coloca como communicative approach' então ela [ a abordagem ] é bem assim /eu falo e eles vão repetindo((fala vagarosamente e quase sussurando)) / e depois eles vão construindo frases a partir do que eu vou repetindo/ quem elaborou o material acredita que aprender língua é aprender vocabulário /e a partir disso ir formando frases construindo frases estruturando outras frases 
Professora C.

por conta de uma questão de tempo de você ter que cumprir programas/ alguma coisa assim / eu sempre tenho a impressão de que a coisa fica meio neglected/ poderia dar mais atenção à determinadas coisas que eu não posso porque tenho um programa a cumprir tenho alguma coisa a fazer por isso não pode passar mais tempo onde você acha que os alunos precisam

Faz-se necessário deixar claro que Miller concebe gênero como entidade constitutiva e comunicativa da sociedade, um componente organizador da estrutura social (op.cit). Para que uma comunidade virtual, então, não se dissipe, e mantenha a sua unicidade, Miller propõe três forças centrípetas que são retoricamente disponíveis: o gênero, a metáfora e a narrativa.

Aos gêneros - a primeira força - Miller (1984, p.37) atribui a função de mediar intenções privadas e exigências institucionais. Por esse prisma, a ampliação do uso dos relatos de professores que testemunhamos a cada dia, serve, em linhas gerais, para legitimar a filosofia da prática reflexiva, possibilitando aos professores a sua inserção em um grupo que se denomina pesquisador e teorizador da sua prática.

O segundo aspecto analisado pela autora - a dimensão da metáfora - fornece uma riqueza de caminhos que levam às similitudes e às diferenças que fazem sobressair o comum, a unificação do que poderia se constituir divisão. Para Telles (1999), as metáforas nos ajudam a compreender como os professores relacionam a dicotomia teoria/prática ao seu fazer pedagógico ${ }^{6}$. Através das imagens, é possível percebemos essa relação. Para ilustrarmos a dimensão da metáfora nos relatos de professores, vejamos alguns excertos de fala:

Finalmente, Miller considera a narrativa como a terceira força centrípeta, esta tendo a função de construção da comunidade. Nesta linha de pensamento, Rouse (1990, p.84 apud MILLER, op.cit, p 75) observa que a cidadania nas comunidades é

\begin{abstract}
${ }^{6} \mathrm{~A}$ problemática da metáfora não se enquadra em nosso estudo. Para uma leitura sobre metáfora e o conhecimento pessoal prático do professor de Língua Estrangeira, ver João Telles (1999).
\end{abstract}


7 " $[\ldots]$ constituted in substantial part by sharing [a] past as a basis for further action. And by our accountability (to ourselves and others) for the intelligibility of those actions in terms of that past. In effect we must be able to tell ourselves and others, stories about that past and our location in it." constituida substancialmente pelo compartilhamento de [um] passado como base para ação complementar. E pela responsabilidade (para com nós mesmos e com os outros) para a inteligibilidade dessas ações em termos desse passado. $N a$ verdade devemos ser capazes de contar a nós mesmos e a outros, histórias sobre esse passado e a nossa localização nele. (grifos nossos) ${ }^{7}$

Ao considerar e adotar a teoria da estruturação de Giddens, Miller (1994. p.70) nos fornece pistas de como entender a estrutura social representada no discurso individual que está, certamente, encharcado de representações mentais sociais que organizam a nossa experiência e que são, por ela, organizadas. Um aspecto interessante, no entendimento dessa teoria, é o fato de estarmos aqui considerando que a estrutura, embora virtual, deve ser realizada no espaço e no tempo de uma realidade material. Os indivíduos são aqueles que criam seus índices sociais de ação, seu conhecimento. Eles fazem isso, segundo a autora, a partir da recursividade que há nas estruturas disponíveis, classificações e interpretações partilhadas.

A conduta dos indivíduos é, em grande parte, resultado da reprodução que fazemos das estruturas sociais e culturais da coletividade. Isto significa dizer que podemos buscar, nos discursos dos professores, o que é partilhado, o que pertence ao social. Assim, novas práticas sociais estimulam mudanças nas práticas discursivas que ganham, por sua vez, novas expressões, influenciando não só as relações sociais e identidades sociais e profissionais (FAIRCLOUGH, 2001, p. 25), mas também criando novos parâmetros para condutas e modos de agir. No campo do ensino de línguas estrangeiras, a inserção de expressões como professor facilitador, por exemplo, fortalece e cristaliza a reprodução de um conhecimento que circula nesse grupo social de que o professor deve ser aquele que está em sala de aula para facilitar o processo de ensinoaprendizagem, pois deve promover/encorajar a autonomia 
dos alunos com relação ao seu próprio aprendizado. Vejamos como o termo é recorrente nas falas das professoras $\mathrm{C}$ e I.

\section{Professora $C$.}

eu acho sabe/ que o professor ele/ hoje usa-se muito o termo facilitador né?/ não mais professor.../ mas eu acho assim que o papel social / eu acredito que o professor ele tem uma capacidade de integrar muito grande...

\section{Professora $I$.}

porque é aquela história do ensino / não é o professor que tá ali para ensinar e o aluno tá ali só para ser passivo só para aprender né? / ele [ o aluno] já traz tudo / eu já tenho consciência que ele traz conhecimento ele traz tudo e ali a gente vai trocar né? muitas coisas e que assim eu tô ali pra facilitar né?

A concepção de um professor facilitador, já há muito institucionalizada no ensino de língua estrangeira, deixa traços nas falas das professoras. Através desses fragmentos, percebemos tanto índices indiretos (hoje usase muito o termo facilitador) e índices diretos (eu tô ali pra facilitar) de uma configuração identitária assumida por ambas as professoras, que ressaltam a importância de se assumirem enquanto facilitadoras, pois esta é a conduta que se espera que adotem.

\section{A maleabilidade do gênero relato}

Assim como podemos atestar a enorme variabilidade e plasticidade dos gêneros textuais, os relatos orais e escritos não possuem uma estrutura ou forma preestabelecida. Funcionam como uma narrativa pessoal, muitas vezes num estilo bastante informal, corroborando o que Marcuschi (op.cit., p.25) entende como gênero, um "[...] ]evento textual altamente maleável, dinâmico e plástico". 
Para efeito de ilustração, selecionamos três segmentos introdutórios de relatos escritos por professores de inglês durante um mini-curso intitulado Desenvolvimento de professores: uma abordagem reflexiva, ministrado em uma escola de línguas da cidade de João Pessoa.

\section{Segmento 1}

Minha aula poderia ter sido mais eficiente. $O$ barulho dos alunos, muitas vezes é desestimulante. Apesar do controle que possamos exercer sobre eles. Nessa aula em particular estavam muito agitados e eu senti dificuldade em controlá-los.

\section{Segmento 2}

coservei que fiqued sentado por mulo termo no mesmo lugat - na frente da sala no meso. Eu jedua tentar andar mas na sala de aula portante gosto de esta no musmo nível (contato de oldes) dos alunos porque acho mas intimo

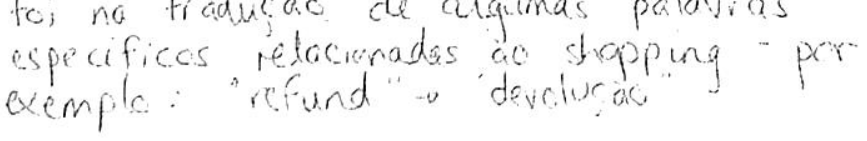

\section{Segmento 3}

Nos dias quatro e seis de novembro das 14:15 às 15:30 gravei em mini fita as aulas da turma do estágio 6. É uma turma composta de treze alunos na faixa etária dos doze aos catorze anos. Eles são na maioria muito responsáveis e atentos às explicações embora às vezes conversem um pouco além da conta em língua portuguesa. 


\section{Segmento 4}

Teaching for me is a world of discoveries. I never thought that I would be a teacher someday. But I had the opportunity and I decided to take it. And I love it. I thought that I would not be able to teach children and teenagers, but it was a wonderful surprise. This does not mean that I did not have any kind of problems. I had plenty of them and they happen all the time. However, I know already how to deal with them.

[Ensinar para mim é um mundo de descobertas. Eu nunca pensei que eu seria professor um dia. Mas eu tive a oportunidade e decidi aceitá-la. E eu amo ensinar. $\mathrm{Eu}$ pensei que não seria capaz de ensinar crianças e adolescentes, mas foi uma surpresa maravilhosa. Isto não significa que eu não tive nenhum tipo de problemas. Eu tive muitos deles e eles acontecem o tempo todo. Porém, eu já sei como lidar com eles.]

Os exemplos apresentados atestam a maleabilidade do gênero sobre o qual estamos tratando. No primeiro caso, o professor, ao mesmo tempo em que descreve a atmosfera da aula e o que, efetivamente, aconteceu, também emite a sua opinião concernente ao comportamento dos alunos. No exemplo seguinte, o professor, no entanto, se atém às justificativas de como se posiciona na sala e no uso da língua-alvo. No terceiro segmento, a professora introduz o seu texto como se estivesse redigindo um relatório, isto é, citando data, horário, perfil dos alunos etc. Diferentemente, no exemplo 4 , o professor opta por redigir em língua inglesa, elaborando um texto que foge à descrição da sala e dos comportamentos dos alunos, mas que centra nos seus sentimentos em relação ao ensino de língua estrangeira, nas suas apreensões e alegrias.

Essa propriedade da narrativa - de ser flexível e pender para o estilo de cada professor, mais ou menos formal, por exemplo - enquadra-se, a nosso ver, no argumento de Bronckart (1999), de que determinados gêneros têm propriedades singulares, isto é, apresentam valores de quem o produz e que, sendo assim, não se pode 
detectar uma correlação direta entre gênero e características lingüísticas formais.

$\mathrm{Na}$ realidade, o que mais nos interessa é que, em sua essência, esse tipo de discurso reside na possibilidade de (re) contar, para os outros e para si mesmo, a história de professor que cada um tem, num processo de terapia de aulas passadas. Como afirmou Bronckart (1999, p.103 apud MARCUSCHI, 2002, p. 29) "[...]a apropriação dos gêneros é um mecanismo fundamental de socialização, de inserção prática nas atividades comunicativas humanas".

\section{Considerações Finais}

Sabemos que é nas práticas sociais que o homem se constitui enquanto tal, conhecendo e dando a conhecer, desenvolvendo sua linguagem e seu pensamento. Nesta linha de raciocínio, entendemos que as narrativas de professores promovem não apenas a interação voltada à ampliação dessa prática entre aqueles envolvidos em um processo de desenvolvimento profissional, mas também servem, dentre outros propósitos, como elemento orientador para uma prática discursiva no campo da formação de professores, auxiliando-os no seu posicionamento e, ao mesmo tempo, na construção das várias faces de suas identidades.

Para Miller (op.cit.,p. 71), os próprios atores sociais criam a recorrência em suas ações, ao reproduzirem os aspectos estruturais de instituições. Estas estruturas estão disponíveis sempre que dela precisemos para efeito de memória, interpretação e uso. Por esse prisma, podemos entender o relato de experiências na formação de professores como uma forma de sistematização retórica da experiência do professor: uma maneira de manter unificado o que parece heterogêneo e diferenciado. Através das narrativas, percebemos quão diferentes e singulares são os momentos de sala de aula, mas ao mesmo tempo, nos damos conta de que estes momentos são versões recorrentes de tantos outros momentos de sala de aula vividos por outros professores. O relato - visto 
dessa forma - pode até servir para ratificar ou questionar atitudes e crenças, mas jamais para desvincular um professor da sua comunidade retórica. 


\section{Referências}

BAKHTIN, Michail. Estética da criação verbal. 3ed. São Paulo: Martins Fontes, 2000[1953].

BATHIA, Vijay. Analysing genre: language use in professsional settings. London: Longman, 1993.

BAZERMAN, Charles. Systems of Genres and the Enactment of Social Intetions. In.: FREEMAN, Aviva; MEDWAY, Peter (Eds.) Genres and the new rhetoric. London: Taylor\& Francis, 1994. p 79-101.

BRONCKART, Jean-Paul. Atividade de linguagem, textos e discursos:por um interacionismo sócio-discursivo. São Paulo: EDUC, 2003 [1997].

DOLZ, Joaquim; SCHNEUWLY, Dolz. Genres et progression em expression orale et écrite. Éléments de reflexions à propôs dúne epérience romande. Enjeux Revue de Didactique du Françai, 37/38, p. 48-74, 1996.

FAIRCLOUGH, Norman. Discurso e mudança social. Brasília: Editora da UnB, 2001[1989].

HALLIDAY, M.A.K; HASAN, R. Language, context and text: Aspects of language in a social- semiotic Perspective. Oxford: Oxford University Press, 1989.

MARCUSCHI, Luiz Antônio. Gêneros textuais: definição e funcionalidade. In.: DIONISIO, Ângela Paiva; MACHADO, Anna Rachel; BEZERRA, Maria Auxiliadora. (orgs.). Gêneros textuais e ensino. Rio de Janeiro: Editora Lucerna, 2002a. p. 19-46.

MILLER, Carolyn. Genre as social action. In.: FREEMAN, Aviva ; MEDWAY, Peter (Eds.) Genres and the new rhetoric. London: Taylor\& Francis, 1984. p 23-42.

.Rhetorical Community: the cultural basis of genre. In.: FREEMAN, Aviva ; MEDWAY, Peter (Eds.) Genres and the new rhetoric. London: Taylor\& Francis, 1994. P. 67-78.

MONDADA, Lorenza. Cognition et parole-en-interaction. In.: VEREDAS: Revista de estudos lingüísticos. vol.6, n.1- jan/jun, 2002. p.9-27.

SWALES, J.M. Genre analysis. English in academic and research settings. Cambridge: C.U.P, 1990. 
TELLES, João Antônio. A trajetória narrativa: histórias sobre a formação do professor de línguas e sua prática pedagógica.

Trabalhos em lingüística aplicada, Campinas, n. 34, p. 79-92, 1999a.

VIRTANEN, Tuija. Issues of text typology: Narrative - a 'basic' type of text? London: Longman. 1992.

WEINRICH, Harald. Estructura y function de los tiempos en lenguaje. Madrid: Editorial Gredos, 1968. 